\title{
APPLICATION OF WEB BASED TECHNOLOGIES FOR IMPLEMENTATION OF AUTOMATED SMART CITY SERVICES
}

\author{
$U D C(004.692 .622: 621.39)$
}

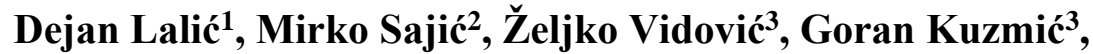 Dušanka Bundalo ${ }^{4}$, Zlatko Bundalo 5}

\author{
${ }^{1}$ NLB Banka a.d. Banja Luka, Banja Luka, Bosnia and Herzegovina \\ ${ }^{2}$ Sberbank ad. Banja Luka, Banja Luka, Bosnia and Herzegovina \\ ${ }^{3}$ University of East Sarajevo, Faculty of Transport and Traffic Engineering, Doboj, \\ Bosnia and Herzegovina \\ ${ }^{4}$ University of Banja Luka, Faculty of Philosophy, Banja Luka, Bosnia and Herzegovina \\ ${ }^{5}$ University of Banja Luka, Faculty of Electrical Engineering, Banja Luka, \\ Bosnia and Herzegovina
}

\begin{abstract}
The paper considers, proposes and describes possibilities and methods to solve problems in providing services in smart cities, where citizens have to appear in person in the city or municipality premises or at the teller/counter of the institution. In this way, by using information and telecommunication technologies, Web based solutions and Internet, citizens obtain services online, from their homes or working places, using all types of their PC equipment or smart mobile telephone, and do not waste their time in the city or municipality premises. Their contacts are also reduced, which is very important in the context of actual Corona virus pandemic. The services are provided and charged automatically and online. No cash is used, which is also a potential carrier of the Corona virus. The proposed method and proposed solution are based on application of the specially developed algorithm for service automation, developed and implemented adequate software application and designed hardware solution that fully supports the software solution and the process of service delivery automation. The proposed system decreases costs and increases availability, quality and speed of services realization in smart cities and municipalities. Also, the proposed solution uses reliable methods for identification and authentication of a person using a service. For identification are used pictures, taken by a Web camera or a smart mobile telephone, of an identity document and of the face of the user and appropriate software for text and face recognition.
\end{abstract}

Key words: Digital technologies, information and telecommunication technologies, smart city services, tellers/counters in smart city institutions, algorithm for service automation, hardware and software solutions, web based solutions, Corona virus pandemic, methods for user identification

Received January 11, 2021 / Accepted February 9, 2021

Corresponding author: Zlatko Bundalo

University of Banja Luka, Faculty of Electrical Engineering, Patre 5, 78000 Banja Luka, Bosnia and Herzegovina

E-mail: zlatbun2007@gmail.com 


\section{INTRODUCTION}

The development and expansion of information, telecommunication and mobile technologies, that are basically digital electronic technologies, has led to the change in human activities and life habits around the world. It is normal that this is reflected in the way of performing many business activities and services. All of that has caused that in many areas of business activities, the ways and methods of organizing and providing business services are also very much changed and permanently changing.

Within the general tendency to automate and robotize services, that is performed in the concept called smart city, every service that the city or municipality provides to its residents should be considered [1-5]. A careful consideration of these services should strive to automate and robotize as much as possible of city or municipality services. This will certainly provide an opportunity for these services to be offered and provided online, by enabling and organization of such services using modern digital information and mobile technologies.

The topic of this paper is the analysis and description of the possibilities of automation of services performed in the city or municipality institutions, mainly at the teller/counters of city or municipality institutions. The goal is to develop such algorithms and solutions, which would to a greater extent, to the extent that the law regulations allow, enable the automation and robotization of these services. These are, in fact, different types of city and municipality services, such as the issuance of various certificates, from the registers of marriages, births, as well as various other types of certificates and documents that are issued by the city and municipality or at their counters.

Specifically, in this paper, it is proposed to automate and robotize mentioned types of city services in a way that the services are provided and realized through Web applications, using Web technologies. Using properly designed and implemented Web application every city resident could obtain needed services online. Such obtained document or certificate would be delivered to the citizen or client by e-mail or by regular mail to the address that the citizen/client would specify. All that would be organized and performed by using of new advanced information, telecommunication and mobile technologies.

The goal is to provide the online services of the city and municipality through the proper designed city portal for certain types of services offered by the city and municipality. The portal will enable citizens to:

- Identify themselves through a personal document,

- Choose a city or municipal service,

- Make a payment for a service,

- Delivery of obtained document.

The paper is organized as follows. In Section 2, the concept of the smart city is considered and described, including the basic components and main characteristics of smart city. Possibilities and ways of design and implementation of automated Web based smart city services and teller/counter services using modern digital technologies are described and discussed in Section 3. In the following Section 4, the proposed automated Web based system for smart city services realization and developed services for application in smart city are described. The concluding remarks are given in the last Section 5. 


\section{SMART CITY CONCEPT}

The concept of a smart city considers and deals with the problems of sustainable development of urban areas, cities and municipalities [1-5]. In a such concept, data of a wide range of human life activities are monitored and collected using advanced technologies. Conclusions important for the functioning of the city are drawn from those data. In that, it is necessary to provide the efficient and sustainable development of urban areas. In their development, smart cities are shaped by social, economic and technological progress. Those include visions of the cities of the future, economic progress, market of smart products and the need of cities to find adequate solutions for sustainable development due to accelerated urbanization.

There is no single definition of a smart city. But, there are more of definitions that define term of a smart city in a similar way. International standardization organizations define a smart city as follows:

- International Telecommunication Union (ITU):

- a city that uses ICT and other technologies in innovative ways to improve the quality of life, efficiency of urban services, such as public transport, while enabling meeting the economic, social and environmental requirements of current and future generations.

- International Standardization Organization (ISO):

- the smart city is a new concept and a new model, using a new generation of information technologies, such as the Internet of things, cloud computing and big data to improve planning, management and services in town.

There are six basic components of a smart city:

- Smart economy,

- Smart governance,

- Smart environment,

- Smart life,

- Smart mobility,

- Smart people.

Smart economy refers to all the necessary actions with an aim to transform and strengthen the city economy. The main goals of a smart economy are improvement of the overall business climate, the attractiveness of the city for start-up companies, investors and other companies, as well as the growth of the economy in an innovative and sustainable way.

Smart governance refers to strengthening the links and interactions between the city administration and all stakeholders, citizens, companies and other organizations in the city or municipality. A city government that develops and follows a smart city strategy can increase the quality and scope of services it offers to citizens, companies and other organizations.

Smart environment refers to how the city government manages the natural environment to improve the quality of life of all citizens. Some of the goals of a smart environment are reduction of waste production, monitoring and managing of pollution, reduction of harmful gas emissions, managing of water, and achieving energy efficiency in the city.

Smart living has as an aim to increase the quality of life of city residents for all age groups and demographic categories. Smart living focuses on improving social and digital inclusion (use of electronic services and social platforms), on improving health care and care for the elderly people (e-health), on security and conditions of housing. 
Smart mobility focuses on increasing the efficiency and quality of public transport services. That is realized by introducing digital technologies for monitoring and control of urban transport, through adequate infrastructure investments, supporting combinations of several types of public and private transport and using new forms of transport (electric vehicles, autonomous vehicles, bicycle sharing). The goal is to increase the flow of people and resources within the city, while minimizing the impact on life and the environment.

Smart people is a concept that aims to transform the way people and the public sector communicate. The goal is to create ways for better cooperation between citizens and the city administration, in order to better and easier meet the needs of citizens. That segment of the smart city also deals with the improvement of the education system. This facilitates career choices and gives more opportunities in the job market.

The main problems in the smart city concept are: insufficient privacy and security of personal data, insufficient education, awareness and participation of citizens.

Smart cities are constantly collecting large amounts of data using sensors and cameras, for a number of applications. Therefore, there are suspicions that the constant surveillance with the cameras violates the privacy of citizens. Data security is also a problem because data collected from citizens is often the target of cyber attacks of many malicious individuals or groups.

Education, awareness and participation of citizens are very important for the development of any smart city. Even in developed countries, citizens awareness of smart cities is low. The situation is worse in countries where the literacy of the population is at a lower level. In such countries, a significant part of the population is not sufficiently technically educated and trained. Such citizens are not ready to accept modern technologies in the concept of smart cities.

\section{WAY OF DESIGN OF Web BASEd SMART CITY SERVICES}

Until the appearance and development of modern mobile digital technologies, which enable the automation of a number of jobs, the performing of traditional teller/counter services was possible exclusively with the help of human work. In fact, even then, those were jobs that were repeated cyclically. In a way, those jobs were made with a great degree of automation. However, there was not a technology that would be able to use to automate that automation. Now, it is also very difficult to avoid the use of human work for certain activities, but even in those cases, the degree of automatism has increased significantly. Also, services provided traditionally by using the human work have to be organized and delivered in the service provider premises. Clients have to go to the premises of the service provider and have to be personally present there during realization, delivery and receiving of the needed service.

With the application of new digital Web technologies, with the use of proper hardware and software solutions, it is possible, to implement an automated process that can provide certain teller/counter services [6]. A semi automated or a fully automated process can be implemented. The fully automated process can be implemented in countries where it is possible to use digitally signed documents. The benefits of a fully automated online type of offering, providing and delivering of all kinds of such services are many [7]:

- Possibilities of providing of the service for the people with special needs, people who have difficulties to go in a municipality building,

- Possibilities of providing of the service in period of pandemic and similar situations, 
- In accordance with his/her needs and other obligations, a client may choose the right time to receive the service,

- Clients can receive the service without leaving their home place,

- The place from which the service is provided and organization of the provision of the service is simplified,

- It is realistic to expect that the number and types of such services will be increased, because customer can make a free choice of time and place for realization and receiving of the service and service offering and realization are more simplified than before,

- Client becomes more satisfied because of all mentioned reasons.

One of the important elements in the implementation of the smart city concept is to realize and offer such kind of online services. The purpose of such services is to automate the way of offering online services or teller/counter services in the city or municipality administration. Some of the most significant and the most important such services that could be automated and realized online in a smart city, using a Web organized process of ordering and delivering teller/counter services, proposed and described in this paper are:

- Birth certificate,

- Citizenship excerpt,

- Payment of real estates and taxation,

- Marriage certificate,

- Children birth certificate,

- Cadastre services,

- Various types of certificates and power of attorney,

- Education related services,

- Other services offering from city or municipality organizations and companies engaged in teller/counter service activities.

Consumers of the services can be all citizens of the city or municipality who have the Internet connection and appropriate equipment. In particular, these services are suitable for those citizens who live far from the city or municipal administrative headquarters and premises. Also, potential users are all elderly and ill people who are not able to move around the city, as well as all others who, for any reason, are not able to come to the city or municipality building.

Speed and ease of realization, availability, affordable price and quality of delivery are the basic requirements of users of the described services [8]. However, it is very difficult to meet all this requirements by using the traditional way of providing such services. The first obstacle to satisfy customer needs in case of a conventional way of providing a service, is service availability. It would be very difficult and expensive to provide permanent availability of the services. That creates problems not only for the service user, but also for his employer. The users of these services, using the traditional (conventional) way of providing these services, must realize the services during their working hours, must leave their working places and must go to the service provider premises.

To decrease the costs and to increase availability, quality and speed of services realization in smart cities, it is necessary to use a different type of organization of these services. To achieve all those requirements the following should be realized:

- The process of providing a specific service should be simplified as much as possible,

- The service should be robotized, according to an algorithm of service automation, using modern digital information technologies, in this case using Internet, Web technologies and delivering institutions (only if digital sign is not in use), 
- Develop and implement an proper application that will fully support the process automation,

- Design a hardware solution that will incorporate and fully support adequate software solution with the aim of fully-automated or semi-automated and robotized service delivery.

Higher availability is the key factor that raises quality of services and increases the speed of service delivery. Service robotization and job automation can fulfil most of the basic requirements of the users. There is no doubt that customer satisfaction will be much higher comparing to traditional way of providing these services.

\section{Proposed System FOR Web BASED SMART City SERVICES}

The key element and key point of the proposed solution and system is a database server that will collect data from citizens and through the specially designed Portal. Citizens data will be later sent to the city or municipality server.

If required by the city or municipality, it is possible to implement the system in such a way that the data is not stored on the Portal server at all, but is immediately forwarded to the city or municipality server via a Web service, or in some other way. The data to be processed during realization of the services are:

- Data from the personal document (name, surname, date of validity of the document, date of birth, number of the personal document, etc.),

- Citizen face (optional, if face recognition is required),

- Type of city or municipal service,

- Price of service,

- Type of charge for document delivery (electronic payment card or cash on delivery).

The system uses the most modern visual technologies as are Optical Character Recognition (OCR) software, face recognition software, etc. Some of that technologies have developed ourselves and for some we use Web services from other suppliers. Also, the system uses the most modern Web technologies:

- Web portal:

- On-line real-time data view,

- Graphic and tabular statistic reports,

- Reports export (PDF, XLS, etc.),

- Custom dashboard - user defined reports,

- Administrator panel for arranging Web portal pages,

- Multi-language support (Serbian and English),

- Alarm notifications: SMS and e-mail (adjustable in Admin Panel),

- Responsive and mobile-friendly design,

- Apache latest version,

- PHP latest version.

- Other:

- Redis latest version,

- Rsync latest version. 
Figure 1 shows the proposed model of system of Web based services for usage in smart cities or municipalities. It is important that adequate software solution, which adequately communicates with the city or municipality information system via adequate API function, is implemented and provided.

Figure 1 shows Web based model of digital services or teller/counter services offering in case it functions to support providing of services offered by the municipality and the city.

To obtain the services user can use his/her desktop, laptop, notebook or tablet type PC, as well as his/her smart mobile telephone, with connection to Internet. A used PC should have a connected scanner or an installed Web camera.

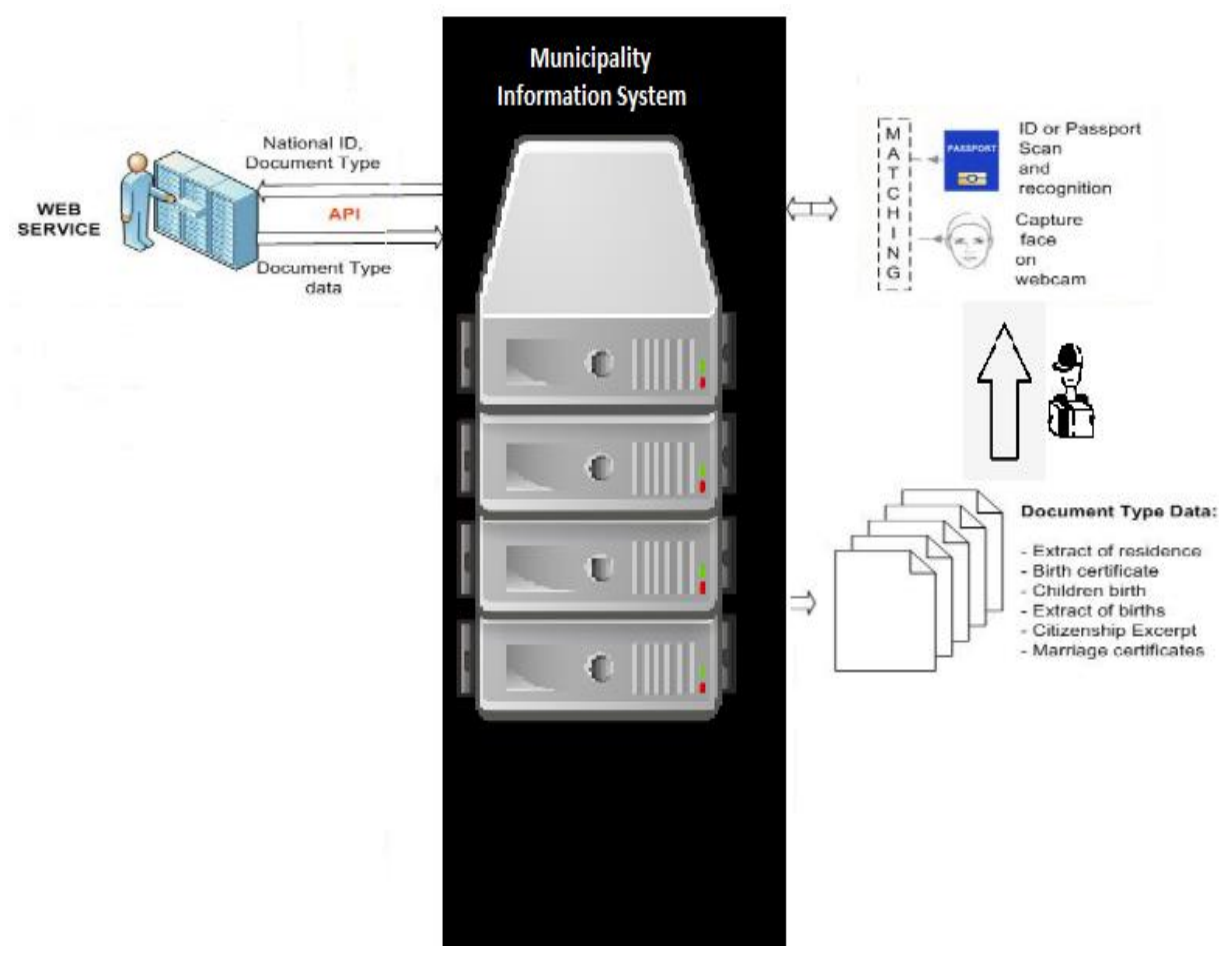

Fig. 1 Proposed model of Web based solution for smart city services

It is envisaged that the identification of the user is performed using a personal identity document of the user, scanned or photographed by Web camera or smart mobile telephone camera. Personal identity documents that can be used are personal identity card (ID card) or passport. During the process of identification the system communicates with the database of the competent institution where the personal identification data are officially stored. Scanned or photographed images (photos) are converted into a text document and the system reads the necessary identification data from those documents. The obtained identification data is checked by comparison with the data from the relevant database to which the system is connected.

Additional verification, if necessary, can be performed by client recognition, using a built-in Web camera on the client PC equipment or smart mobile telephone camera, and face recognition software solution. By using the built-in Web camera or smart mobile 
telephone camera a picture of the client can be taken. By the face recognition software solution, that picture is compared with the user image from the database of the institution where the personal identification data is stored. In addition to the client picture, data on the exact date and time when the service was performed can also be stored. In this way, the presence of the user at a certain time, on a certain date, on the system is uniquely determined, recorded and stored.

Also, by using the built-in Web camera or smart mobile telephone camera, a short video recording of the client can be taken for recognizing that the client in front of the camera is alive.

Information and documents that are not important, not confidential and that do not require an original signature and stamp, can be sent to user immediately by the system or later by regular e-mail. Such information and documents user can print on his/her printer or use it in the electronic form on his/her PC equipment or on smart mobile telephone. Information and documents that are important, confidential and that require an original signature and stamp, can be printed and prepared in the city administration office and sent to user by the regular mail (traditional post service), the express mail (express post service) or by the city delivery service.

Payment of costs for obtained services can be performed online via electronic payment cards. Users that do not use or do not want to pay by electronic payment cards can do it by paying by cash at the moment of document delivering at the client home or business address.

Various types of documents can be obtained, printed and delivered, depending on the type of service required and selected. There is support for the issuance of various types of documents offered by city or municipality. Those documents are otherwise obtained in the city or municipality building.

A specially designed Web application is making connection between the client PC or smart mobile telephone and city or municipality information system. Client can use and access the system by a desktop, laptop, notebook and tablet type PC or by a smart mobile telephone. The city or municipality information system consists of a computer network and an appropriate database of the city or municipality. That enables the Web program to send and receive all the necessary data through that network, all according to the needs and realization of the specific service.

The main menu of the Web software application is shown in Figure 2. That figure shows what type of services are offered to users and cost of service, in case that service is paid. By pressing an appropriate option, a user selects a desired service. After that action, the corresponding submenus are opened. That further leads the user through the application to the desired result, until the final realization of required service.

The main menu of the Web software solution and the way of using the system are almost the same as in the solution described in the reference [8]. In such a way, it is possible for users to obtain automated teller/counter services of smart city or municipality online, from their homes or working places, almost in the same way as during obtaining those services in the city or municipality premises, using universal digital terminal devices.

The specific software implementation, whose main menu was shown in Figure 2, was realized according to the ordered design, using the Power Builder development tool and using the MySQL database. However, the concept of performance is very important, and things like design and technology used are a matter of agreement between the client and the contractor. It is up to the Web site owner to provide all the necessary elements of IT 
security, which will guarantee users discretion on their personal data and availability of the service. Appropriate cryptographic methods can be used and were used for protection of user data and information.

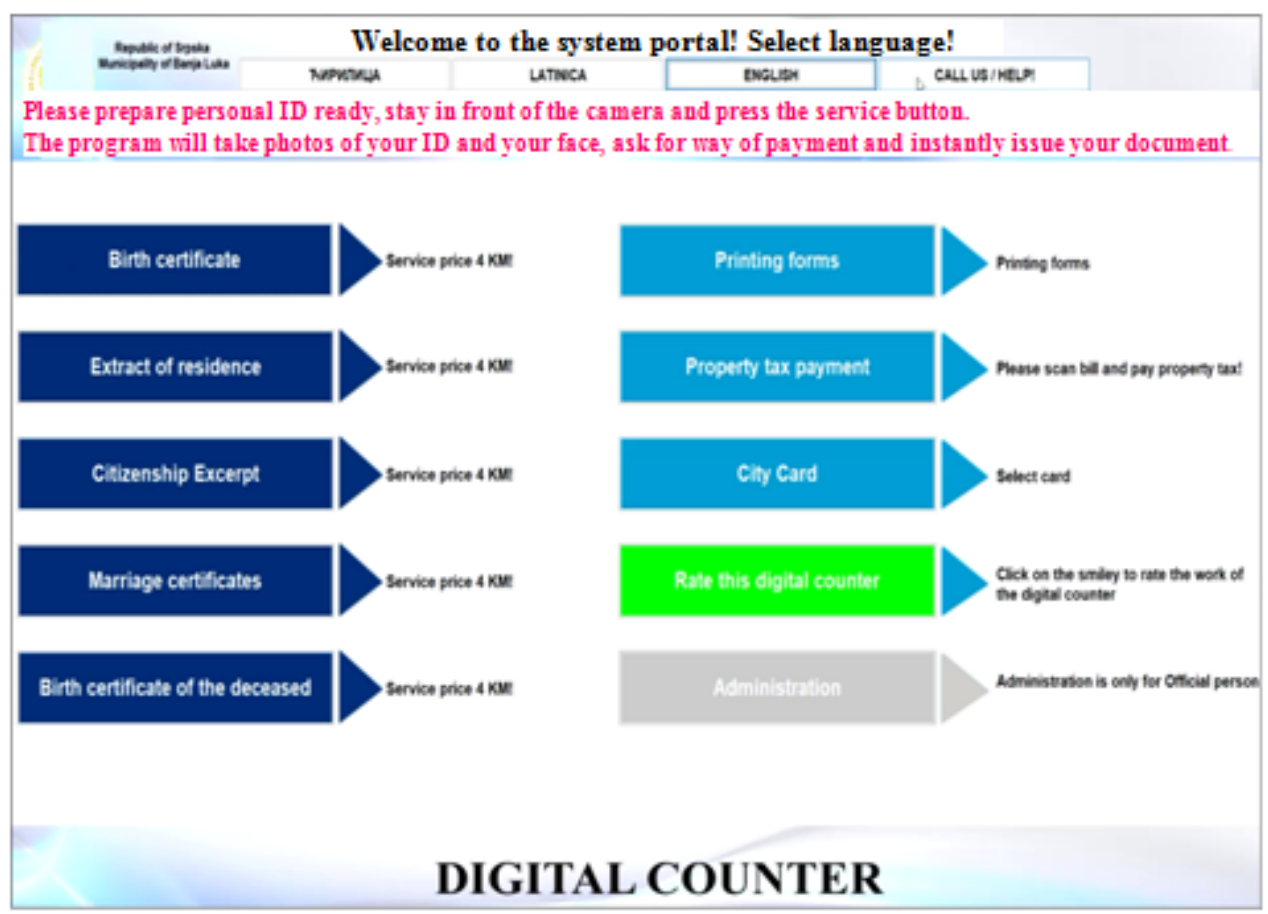

Fig. 2 Main menu of Web based software solution for smart city services

In the system design GDPR (General Data Protection Regulation) regulation directive of the European Union (EU) for protection of user data was considered [9]. It is recommended that all necessary elements of the GDPR regulation directive, that was adopted by EU on 25/05/2018, be respected and applied in the system design. The directive applies in EU member countries, so the introduction of the services described in this paper in EU countries implies obvious compliance with that directive. However, for other countries, especially for the Balkan countries, that are not members of the EU, there is a recommendation to follow the regulations from the GDPR directive at the beginning of the introduction of this and similar services. The process used and described in this paper implies compliance with the GDPR directive, so it should not be a problem to comply with it when it would be implemented here.

The flow of the service, realized by the offered software solution, proceeds as follows:

- The window shown in Figure 2 opens,

- The user chooses which service wants to realize.

- The program requires user identification. The program activates the Web camera on the user computer or camera of the user smart mobile telephone. It takes an image of user and the image of user personal identification document (ID card or passport) and asks 
the user to place the image of the personal document in a designated place in the window and the program. Optical Character Recognition (OCR) software converts the information from the image of the user personal document into textual data form. The program compares such obtained user data with the data from adequate database of users or citizens. Doing so, it performs the process of user authentication and confirms the identity of the user.

- The comparison of the image from the personal document and the image of the user made in the previous step is performed. Face recognition software checks, determines and confirms the identity of the user. Identity can also be determined using some other methods. For example, the method by wich the user pre-registers for these services in the way prescribed by the institution can be used, respecting the law procedures and leaving the necessary identification information (among other things, user mobile telephone number). When user authentication is confirmed, one time password is sent to the user to access the service.

- After the confirmed user identity, the data about service selected by the user is recorded in the database.

- The user selects the next service if wants to realize more services at the same time.

- When the user completes the selection of wanted services, the user receives a notification of the list of accepted services.

- The user receives information when the needed document or documents will be delivered and how much should be paid for those services if it is required.

- The user pays the needed cost of the services if it is required to pay for selected services,

- The program performs and realizes selected services.

As an example of using the system, Figure 3 shows the menu window or submenu for selection of way of service costs payment when the service is to be paid. The user selects one of two possible ways by what he/she wants to pay the service costs. Costs for all services and documents can be paid by the user electronic payment card. Only such types of documents that are delivered to the user by regular mail service, express mail service or by the city delivery service can be paid by cash on delivery time to the user on user defined address.

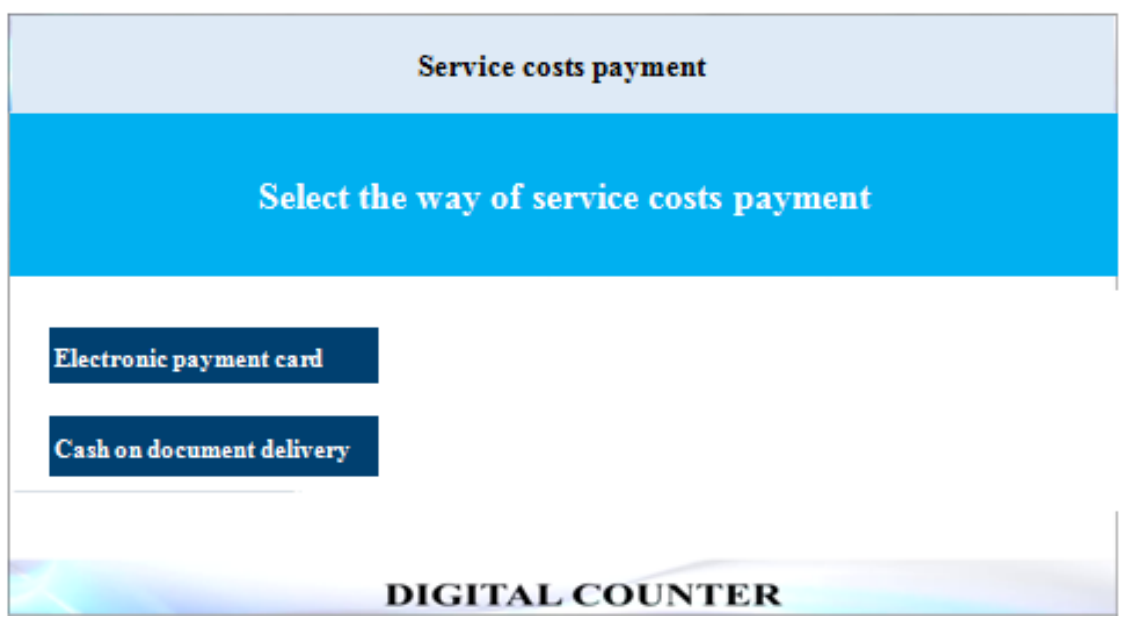

Fig. 3 Menu window for selection of way of service costs payment 
Figure 4 shows the menu window or submenu for selection of the way of service payment by an electronic payment card. There are two possibilities: entering needed data of the electronic payment card or using the picture of the electronic payment card. If the user selects the first possibility he/she then manually enters needed data including account number of the electronic payment card. When the user selects the second option then the program takes the picture (photo) of the electronic payment card, and using the OCR software extracts needed data including account number of the electronic payment card.

The logical order of required activities when choosing services and needed documents allows an easy use of the system and the application. Such ease and logic of use enables the users to use services without problems, to go through the options and to realize the needed service. Since the application is realized in Web technology, it supports all age user groups in terms of visibility and readability of what is seen on the screen. The ability to choose one of the multiple offered languages is also supported.

\section{Service costs payment by electronic payment card}

\section{Select the way of service costs payment by electronic payment card}

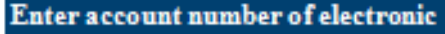

payment card

Use the picture of electronicpayment card

\section{DIGITAL COUNTER}

Fig. 4 Menu window for selection of way of service payment by electronic payment card

Positive results of realization of the described system solution are:

- City administration services available online,

- City administration services available any time from any place,

- Unlike workers, the solution does not make errors and can only be out of order for a certain period of time due to a malfunction,

- Reduced arrival of citizens and reduced social contacts in the municipal building and reduction of traffic jams in the city centre,

- Reduction of the use of cash in circulation in favour of non-cash payments and transactions,

- Reduced possibility of infection by Corona virus or other viruses or bacteria transmitted through social contacts. 


\section{CONCLUSION}

From all the above, there is no doubt that the time will come when changes in the way of providing teller/counter services will be necessary and unavoidable. It is also clear what technologies will be used for that and how such services will be organized in the future. As in other similar situations, the modern technologies such as the Internet, the Web, and other digital mobile technologies are technologies that will be used for realization and automation of such kind of jobs. The proposed method is just one of a number of similar ways in which these services can be realized in terms of automation and robotization of the services. All this is performed and realized in order to meet the needs of the modern user.

Proposed, designed and described system solution is automated and easy for use. It enables users that various types of documents, offered and issued by city or municipality, can easily obtain from distance, online, from their homes or working places. Otherwise, such documents are obtained and issued in the city or municipality building, what requires personal presence of the client. Clients can easily access and use the system and all services by their PC of desktop, laptop, notebook and tablet type or by a smart mobile telephone. The solution is very simple for use, since all activities are realized in a logical order, with easy intuitive navigation through the options to final realization of desired service. It can be easily used by all age groups of users, even by disabled users, and supports multilingual options in all provided services. Also, several ways for user identification, depending on needed security of the service realization are used. The basic way for identification of the user is checking of user personal ID card or passport, scanned or photographed by a Web camera or a smart mobile telephone camera. Additional user identity verification can be realized by client face recognition, using face recognition software and user picture taken from client PC Web camera or smart mobile telephone camera. It can also be checked whether the client in front of the camera is alive, using short video record of the client taken by the Web camera or smart mobile telephone camera. Also, the payment of obtained services costs can be performed online via electronic payment cards or by cash, at the client home or working place address, at the moment of document delivering to the client. Payment of services costs online, by electronic payment cards, reduces usage of the cash money and reduces possibilities for user infection by viruses or bacteria. Depending on the type of required information or document, the information and the documents can be sent to the user immediately by the system or by regular e-mail, or can be prepared in the city administration and sent to user by the regular mail, the express mail or by the city delivery service. The main menu and the way of using the system are almost the same as in the previously proposed and described solution for obtaining automated teller/counter services of smart city from the city promises, using universal digital terminal devices. In such a way, the users can obtain automated teller/counter services of smart city online, from their homes or working places, in almost the same way.

Among many advantages, the main advantages of this solution are:

- No queues of waiting clients in the city premises,

- Reduced workload of municipal employees,

- Reduced corona virus or any other infection or pandemic risk,

- Reduced use of cash money,

- Older and weak people can do it much easier. 
The speed of adoption of the necessary legal regulations (especially the law on digital signature) can be an acceleration factor or a deceleration factor in the process of application of new mobile digital technologies in business automation and robotization. Even the adopted laws still do not guarantee that they practical application will go quickly. An example for that is the law on digital signatures, adopted more than 15 years ago in the Republic of Srpska, that is not yet in the practical application. The reason for that is that it was difficult to choose the certification bodies that will issue digital certificates. It is certain that the pressure of users, who would like to use services like described in this paper, will accelerate the adoption and implementation of the necessary legal regulations for the implementation of mobile and automated services. In the future, it is to be expected that this pressure will be increased. However, the related organizations, in this case the city and the municipality, should also put pressure and start taking activities that will lead to faster implementation of the described online services.

\section{REFERENCES}

[1] C. L. Stimmel, „Building Smart Cities: Analytics, ICT, and Design Thinking”, CRC Press, 2016.

[2] C. Harrison, B. Eckman, R. Hamilton, P. Hartswick, J. Kalagnanam, J. Paraszczak, P. Williams, „Foundations for Smarter Cities,” IBM Journal of Research and Development, 54, 4, 2010, pp. 1-16.

[3] L. Anthopoulos, C. Reddick, „Understanding electronic government research and smart city“, Information Polity, 21, 1, 2015, pp. 99-117.

[4] R. Giffinger, C. Fertner, H. Kramar, R. Kalasek, N. Pichler-Milanović, E. Meijers, „Smart Cities: Ranking of European Medium-sized Cities“, Vienna: Centre of Regional Science, 2007.

[5] P. Lombardi, S. Giordano, H. Farouh, W. Yousef, „Modelling the Smart City Performance,” Innovation: The European Journal of Social Science Research, 25, 2, 2012, pp.137-149.

[6] https://newgensoft.com/products/business-process-management/bpm-robotic-process-automation.

[7] M. Sajić, D. Bundalo, Z. Bundalo, L. Sajić, D. Lalić, G. Kuzmić, ,Smart Universal Multifunctional Digital Terminal/Portal Devices“, Proceedings of 8th International Conference MECO 2019, pp. 171-174.

[8] M. Sajić, D. Bundalo, Z. Bundalo, D. Lalić, G. Kuzmić, „Automation of teller/counter services in smart cities concept using universal digital devices“, 27th Telecommunications forum TELFOR 2019, Serbia, Belgrade, November 26-27, 2019.

[9] http://gdprandyou.ie/ 